\title{
PROPOSTA DE FOMENTO AO EMPREENDEDORISMO A PARTIR DA QUALIFICAÇÃO E TREINAMENTO DE COMERCIANTES AMBULANTES DA CIDADE DO RIO DE JANEIRO
}

\section{ARTIGO ORIGINAL}

BEZERRA, Francisco Canindé Alves ${ }^{1}$

BEZERRA, Francisco Canindé Alves. Proposta de fomento ao empreendedorismo a partir da qualificação e treinamento de comerciantes ambulantes da cidade do Rio de Janeiro. Revista Científica Multidisciplinar Núcleo do Conhecimento. Ano 06, Ed. 05, Vol. 02, pp. 71-92. Maio de 2021. ISSN: 2448-0959, Link de acesso: https://www.nucleodoconhecimento.com.br/administracao/fomento-aoempreendedorismo, DOI: 10.32749/nucleodoconhecimento.com.br/administracao/fomento-aoempreendedorismo

\section{RESUMO}

Tendo em vista que os pequenos negócios representam a força viva da economia Brasileira, sendo, portanto, importante fomentar a formação de micro e pequenas empresas para o crescimento econômico do país, este artigo objetivou propor uma estratégia para a Prefeitura da Cidade do Rio de Janeiro voltada a criação de micro e pequenas empresas em parceria com o SEBRAE, a partir da oportunização do conhecimento, capacitação e treinamento direcionado ao tipo de empreendedor que opera por necessidade, e que trabalha nas ruas da cidade como camelôs. O Serviço Brasileiro de Apoio às Micro e Pequenas (SEBRAE) é uma instituição privada, sem fins lucrativos, mantida pelos repasses das maiores empresas do país, que exerce

\footnotetext{
${ }^{1}$ Graduando Em Administração Pública.
} 
atividades de utilidade pública, voltadas para o estímulo do crescimento sustentável das micro e pequenas empresas e desenvolvimento do empreendedorismo. Sendo assim, tratando-se de uma pesquisa bibliográfica, verificou-se que o fomento a criação das micro e pequenas empresas, a partir deste tipo de empreendedor, proporcionará o desenvolvimento econômico territorial, gerando empregos, renda e melhorando a qualidade de vida da população. Para tanto, será proposto à prefeitura da Cidade do Rio de Janeiro este plano de ação, que cria um ambiente favorável para estimular a abertura de micro e pequenas empresas, o que vai de encontro com as expectativas municipal de crescimento e de desenvolvimento econômico, além de mitigar o crescimento desordenado da informalidade nas ruas da cidade.

Palavras-chave: Empreendedorismo, comércio informal, desenvolvimento econômico.

\section{INTRODUÇÃO}

O livro "Capitalismo, Socialismo e Democracia", escrito pelo economista Schumpeter (1942), descreve a ligação do empreendedorismo com o desenvolvimento econômico de uma região. Para o autor a figura do empreendedor mundo afora é sinônimo de desenvolvimento econômico, pois expõe a competitividade entre os diferentes agentes efetivos da transformação de uma sociedade, promovendo a criação de novas vagas de empregos, gerando renda, riqueza e impactando no desenvolvimento das economias nos âmbitos municipais, estaduais e federal.

O Serviço Brasileiro de Apoio às Micro e Pequenas (SEBRAE) é uma instituição privada, sem fins lucrativos, mantida pelos repasses das maiores empresas do país, que exerce atividades de utilidade pública, voltadas para o estímulo do crescimento sustentável das micro e pequenas empresas e desenvolvimento do empreendedorismo.

Segundo o SEBRAE, as micro e pequenas empresas são de suma importância para o Brasil, "os pequenos negócios são a força viva da economia do Brasil. Eles

RC: 84394

Disponível em: https://www.nucleodoconhecimento.com.br/administracao/fomento-aoempreendedorismo 
representam $98 \%$ das empresas do país, são responsáveis por $54 \%$ dos empregos formais, $30 \%$ de toda a riqueza nacional e estão presentes em $100 \%$ dos municípios brasileiros". As micro e pequenas empresas são responsáveis por acirrar a competitividade na venda de seus produtos e na prestação de seus serviços, o que contribui de forma efetiva para melhora da economia em seu território.

"O papel do empreendedorismo no desenvolvimento econômico envolve mais do que apenas o aumento de produção e renda per capita; envolve iniciar e constituir mudanças na estrutura do negócio e da sociedade" (HISRICH e PETER, 2004). fomento à formação de micro e pequenas empresas pode significar crescimento no número de empregos formais, geração de renda, desenvolvimento econômico, impactando positivamente nas arrecadações aos cofres públicos.

Para Rammé (2011) as potencialidades locais precisam ser encontradas e trabalhadas de forma singular, de acordo com suas características espaciais, culturais, sociais e econômicas, para que seja possível alcançar um crescimento econômico eficaz.

Desenvolver um programa pioneiro de inclusão, numa parceria entre a Prefeitura da Cidade do Rio de Janeiro, o Sebrae e os empreendedores que hoje trabalham como camelôs nas ruas da cidade, promoverá uma singular mudança na vida dessas pessoas, tornando-se uma ótima alternativa de arrecadação para os cofres públicos da Prefeitura do Rio, pois como tantas outras cidades do País, atualmente em função da Pandemia provocada pelo "Coronavírus", passa por dificuldades financeiras. Esta proposta de fomento à criação de micro e pequenas empresas vislumbra o aumento de novos postos de trabalho com carteira assinada, a aceleração da economia territorial, aumento da renda, aumento na arrecadação a partir da cobrança de impostos, além de outros impactos positivos.

Este autor não vislumbra pôr fim ao desordenamento urbano causado pela aglomeração dos camelôs nas ruas da cidade, e nem tampouco considera que todos

RC: 84394

Disponível em: https://www.nucleodoconhecimento.com.br/administracao/fomento-aoempreendedorismo 
os vendedores ambulantes se tornarão empresários, porém, manter esta atual visão holística acerca dos empreendedores ambulantes é negar as mudanças nos processos de ocupação do solo urbano, das práticas urbanas. É necessário ampliar as opções, as possibilidades a estes trabalhadores, cheios de vontade de empreender, mas com pouco conhecimento, pouca orientação e poucas oportunidades. Certamente, o fluxo da mobilidade social restringe às classes mais pobres e as classes mais ricas em suas respectivas posições na pirâmide social. Segundo Vieira (2012), os empreendedores que vêm da parte de cima da pirâmide social, que receberam uma criação mais estruturada, tendo acesso a todo tipo de suporte instrucional, suporte financeiro, além de outras orientações necessárias, que não são empreendedores por necessidade, percorrem o caminho da formalidade empresarial, tornando-se empresários, mantendo-se ricos. Já os empreendedores que integram a base da pirâmide social, que teve uma criação menos estruturada, empreendem por necessidade, e encontram nas ruas da cidade a única possibilidade de exercerem suas atividades empreendedoras, justamente por terem pressa, pouco conhecimento e nenhum preparo, geralmente se mantêm pobres. Uma parceria entre o governo municipal da cidade do Rio de Janeiro e o Sebrae, num projeto que visa dar oportunidades àqueles empreendedores, que não tiveram a chance de ter acesso às informações necessárias para empreenderem de forma diferente, sem ser por necessidade, certamente revelará novos empresários, o que certamente crescerá na arrecadação municipal.

Contudo, é necessário deixar claro a seguinte situação: embora a ideia de mobilidade social se concentre nos processos de ascendência e queda econômica, o seu grande fluxo se concentra em determinada faixa da pirâmide econômica da sociedade. Isso porque os ocupantes da grande base onde se concentra a maior parte da população mundial constituída por pobres e miseráveis, em geral, permanecem na base. Não passam por um fluxo ascendente de maneira significativa. Por isso, podemos dizer que ela é uma camada de caráter relativamente estático. Os mais pobres dificilmente saem desta posição. Por outro lado, os pertencentes ao pico da pirâmide, uma grande minoria, constituída de milionários e bilionários, dificilmente descendem na hierarquia socioeconômica. Permanecem sempre no

RC: 84394

Disponível em: https://www.nucleodoconhecimento.com.br/administracao/fomento-aoempreendedorismo 
pico. Por isso, também compreendem uma camada estática da pirâmide em questão (VIEIRA, 2012, p. 5).

\section{APRESENTAÇÃO DO CASO}

Atualmente, a Cidade do Rio de Janeiro, assim como outras cidades do País, sofre com o aumento do desemprego crescente. O processo da globalização ocorrida na década de 1990, fez aumentar o desemprego nas nações menos desenvolvidas, Harvey (1992). Não obstante, o desemprego atualmente é potencializado pela pandemia provocada pelo COVID-19, já que governos se viram forçados a adotarem - lockdown[2] como estratégia para conter a propagação do vírus, e consequentemente viram também subir o número de desempregados em seus países. As demissões por parte das empresas foram inevitáveis, já que a circulação dos consumidores deixou de existir. Segundo um estudo da Confederação Nacional do Comércio de Bens, Serviços e Turismo (CNC) mais de 50.000 empresas do setor de turismo fecharam as portas. Diante dessa crise econômica vivida no mundo, no Brasil e em nossa cidade, investir no empreendedorismo em parceria com o Serviço Brasileiro de Apoio às Micro e Pequenas Empresas, focando no empreendedor das ruas, capacitando-o, treinando-o e estimulando-o, ampliando seus horizontes como empreendedor, avultando de forma técnica seus potenciais competitivos, pode ser um fator de aumento no número de empregos formais, trazendo benefícios pro desenvolvimento econômico territorial, contribuindo na melhora da situação fiscal do município do Rio de Janeiro.

O terceiro setor tem como regime jurídico o direito privado, podem qualificar-se como Organizações da Sociedade Civil de Interesse Público, sem fins lucrativos. Os serviços sociais autônomos não são administrados ou prestam serviços ao público por delegação do Estado, mas sim em parceria com o mesmo. Suas ações são destinadas a beneficiar determinados grupos sociais ou profissionais, geralmente ligados ao aprendizado profissionalizante e à prestação de serviços assistenciais. Realizam atividades privadas de interesse público, operando junto ao Estado nas atividades,

RC: 84394

Disponível em: https://www.nucleodoconhecimento.com.br/administracao/fomento-aoempreendedorismo 
setores e serviços que lhes são destinados, considerados de caráter específicos de determinados beneficiários, e por isso são incentivadas pelo poder público. Estas empresas do terceiro setor, por administrarem verbas provenientes de contribuições parafiscais e desfrutarem de privilégios de entes públicos, estão sujeitos às normas semelhantes às da Administração Pública, assim sendo devem obedecer aos princípios licitatórios impostos aos órgãos públicos, respondendo por improbidade administrativa, além de serem auditados pelo Tribunal de Contas da União as entidades do "Sistema S", como o Sebrae, é um exemplo de serviços sociais autônomo. Em parceria com o Sebrae/RJ, que é uma entidade sem fins lucrativos, que realiza um importante papel no crescimento e desenvolvimento em nosso Estado, a prefeitura do Rio de Janeiro poderia dar início a este projeto, demonstrando iniciativa empreendedora também por parte do governo municipal. O Sebrae tem como missão fomentar o desenvolvimento sustentável das micro e pequenas empresas, algo muito importante para nossa cidade, visto que esses negócios de pequeno porte representam $98 \%$ de todas as empresas do país. O Sebrae/RJ está presente em 5 escritórios espalhados pelo município do Rio, tendo como sede, o escritório no centro da cidade do Rio de Janeiro. O Sebrae/RJ desenvolve atualmente diversos projetos de norte a sul do Estado, através de recursos públicos, onde as ações incluem capacitação de empresários e suas equipes, estímulo ao empreendedorismo, à inovação e difusão de informações e novas tecnologias.

RC: 84394

Disponível em: https://www.nucleodoconhecimento.com.br/administracao/fomento-aoempreendedorismo 
Imagem 01: Dos 684 mil novos ocupados, $87,1 \%$ estão no mercado de trabalho informal

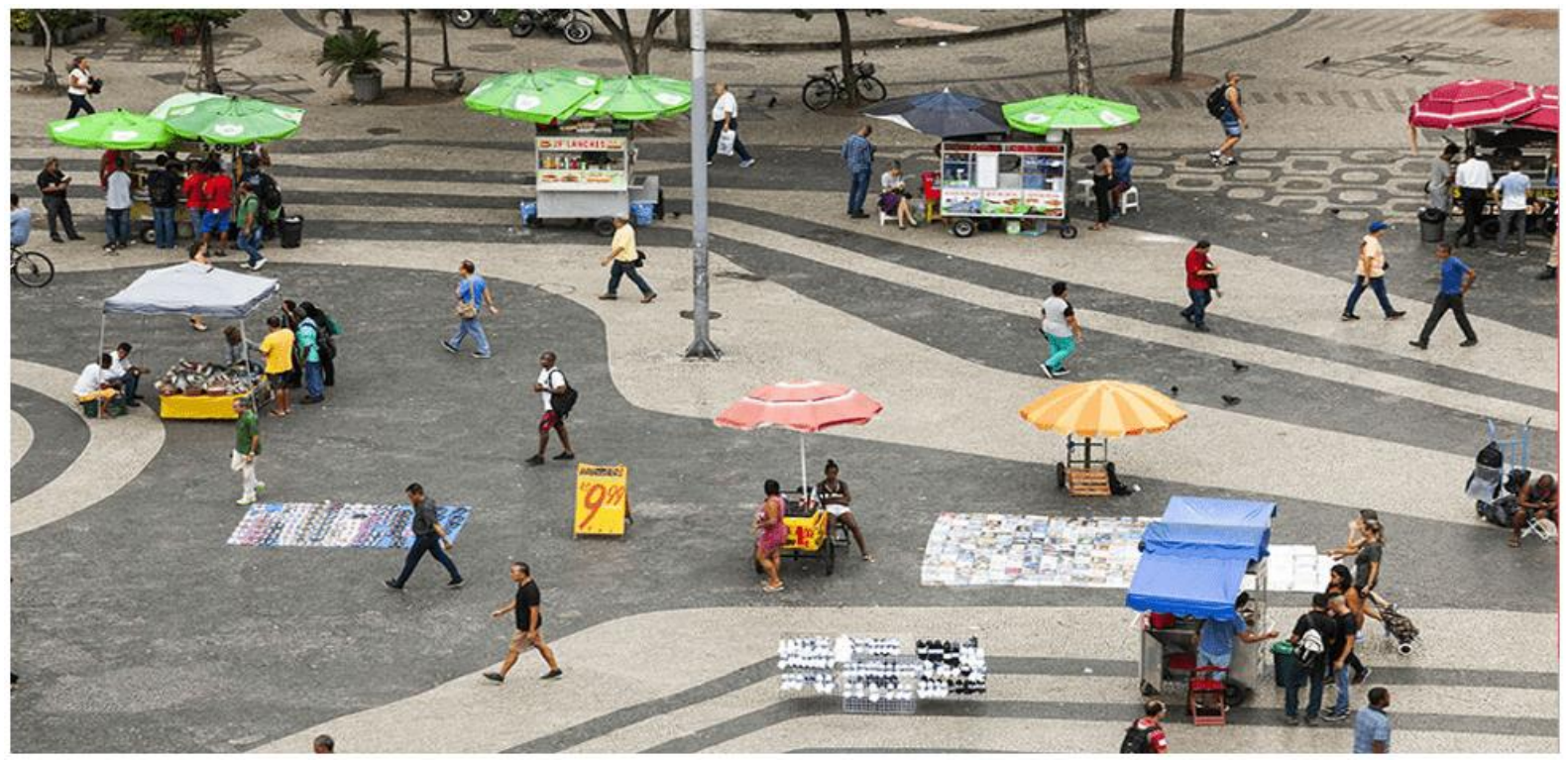

Fonte: Licia Rubinstein/Agência IBGE Notícias

No centro da cidade temos um celeiro de empreendedores, alguns precisam apenas ser lapidados. O exemplo do camelô David Portes, que iniciou sua fase empreendedora em 1986. Aos 45 anos de vida, no momento mais difícil de sua vida, sem emprego, sem casa e com apenas 12 reais no bolso para comprar remédio para sua esposa, que estava grávida, resolveu arriscar e comprou alguns doces para revenda, logo percebeu que já havia dobrado seu capital. Portes viu nas ruas do Centro do Rio a oportunidade comercial de que precisava para ganhar dinheiro. Assim sendo, estabeleceu-se no local onde se destacou entre os demais camelos daquela região, graças ao seu talento singular de encantar seus clientes. Com tanto sucesso e algumas aparições na imprensa, Portes foi convidado a participar de uma palestra em São Paulo, na plateia estavam grandes empresários e políticos nacionais. "Eu atendi o telefone e disse 'senhor, ainda não fazemos delivery para São Paulo' e a pessoa do outro lado da linha respondeu 'não queremos comprar doce, mas sim conhecimento". Minhas pernas tremeram". Nascia então o empresário e palestrante 
David Portes, cujo sucesso e reconhecimento veio de vez em 2006, quando o excamelô recebeu o prêmio de melhor palestrante do mundo pela World Confederation of Businesses (Confederação Mundial de Negócios), o que abriu de vez as portas para o exterior. Hoje Portes relata que já realizou palestras por países como os Estados Unidos, China, Japão, Portugal, Uruguai e Argentina. "A maioria das pessoas fica apenas na boa ideia e não passa para a ação. A diferença está naqueles que conseguem tirá-las do papel e transformá-las em realidade. O que é pior? Se arrepender de algo que fez ou do que não fez?".

Embora o caso do ex-camelô David Portes nos surpreenda, dentre os camelôs mais famosos do Brasil, o que mais se destaca é sem dúvidas o senhor Sílvio Santos. Nascido na Lapa, no Rio de Janeiro, dono de uma voz potente, aos 14 anos empreendeu pela primeira vez nas ruas do centro do Rio como camelô, ali vendeu canetas, porta títulos, além de outras mercadorias. Nessa época começou a frequentar programas de auditórios na Rádio Nacional. Aos 18 anos alistou-se e serviu como paraquedista em Deodoro e como não podia mais ser camelô nas ruas da cidade, pediu ao locutor da Rádio Mauá, Celso Teixeira, que lhe arrumasse algum trabalho. Depois foi locutor da Rádio Tupi e nessa época aproveitava o tempo livre para vender relógios, tecidos, joias e sapatos, nas repartições públicas, escritórios e em obras pela cidade. Depois Sílvio foi ser locutor na Rádio Continental que ficava em Niterói. Neste trajeto que a barca fazia, da cidade do Rio a Niterói, ele teve a grande ideia de criar um serviço de alto-falantes, depois introduzindo músicas e na sequência um bar, dentro da barca. O jovem expedito foi trabalhar na Antártica e sendo eleito o melhor vendedor de produtos da empresa foi por isso levado a São Paulo. Lá chegando, conheceu a Rádio Nacional onde fez teste e foi contratado como locutor. Convidado por Manoel da Nóbrega, Sílvio apresentou o programa "Cadeira de Barbeiro", na época em que Hélio de Souza deixou a Rádio Nacional. Para ganhar mais dinheiro, o jovem talentoso fez shows em circo, promoveu caravanas etc. Sílvio era imparável. Em 1956 assumiu o Baú da Felicidade onde vendia e entregava as mercadorias. Com o decorrer do tempo o ex-camelô foi criando e associando novas

RC: 84394

Disponível em: https://www.nucleodoconhecimento.com.br/administracao/fomento-aoempreendedorismo 
empresas, entre elas: Publicidade Sílvio Santos Ltda, uma companhia de seguros, uma construtora, uma financeira, uma concessionária de carros, uma seguradora, entre outras. Em paralelo a todas as atividades empresariais, o empreendedor iniciou o programa de TV "Vamos Brincar Comigo", na TV Paulista. O sucesso foi tão grande que a TV Globo comprou a TV Paulista. Até que em 1972 surgiu a oportunidade de comprar 50\% da TV Record, e em 1975 o talentoso empresário Sílvio Santos conquistou então o seu canal de televisão em São Paulo. E finalmente, em 1981 entrou no ar o Sistema Brasileiro de Televisão (SBT).

O instinto empreendedor não está no cidadão que integra o ápice ou a base da pirâmide social, mas sim no indivíduo. A criatividade e o senso competitivo não permitiram que eles permanecessem inertes às situações que os afligiam, sendo assim decidiram por necessidade empreender nas ruas do centro do Rio de janeiro.

Infelizmente, casos como os citados acima são raros, a praxe é o pobre e ou miserável continuar pobre e ou miserável, enquanto o milionário e ou o bilionário continuem milionário e ou bilionário. Por isso seria fundamental uma intervenção estatal em parceria com o Sebrae na criação de um programa que vise prover apoio, orientações, acesso facilitado a crédito e treinamento técnico, para que mais casos, como os citados acima, deixem de ser exceção. $O$ fomento a criação de micro e pequenas empresas, a partir da abordagem dos empreendedores ambulantes, contribuindo para a economia local, gerando mais empregos e mais renda, revelar-se-á um importante projeto socioeconômico.

Segundo o IBGE, de 2012 a 2021 o número de desocupados vem aumentando. Atingidos pela política Neo Liberal da globalização, iniciada na década de 90 (HARVEY,1992), e potencializada atualmente pela pandemia causada pelo Coronavírus é muito provável que as pessoas sem emprego tendam a tornarem-se empreendedores por necessidade, acumulando-se nas calçadas das ruas da cidade, forçando ainda mais as estruturas do governo. Por isso é tão importante que a prefeitura da Cidade do Rio de Janeiro interceda a favor do empreendedorismo,

RC: 84394

Disponível em: https://www.nucleodoconhecimento.com.br/administracao/fomento-aoempreendedorismo 
trazendo a luz do conhecimento e oportunidades aos que possuem capacidades pessoais possíveis de serem lapidadas, transformando em solução o que hoje é visto como problema social e econômico. O gráfico abaixo ilustra a situação.

Gráfico 01.

Taxa de desocupação, jan-fev-mar 2012 - nov-dez-jan 2021

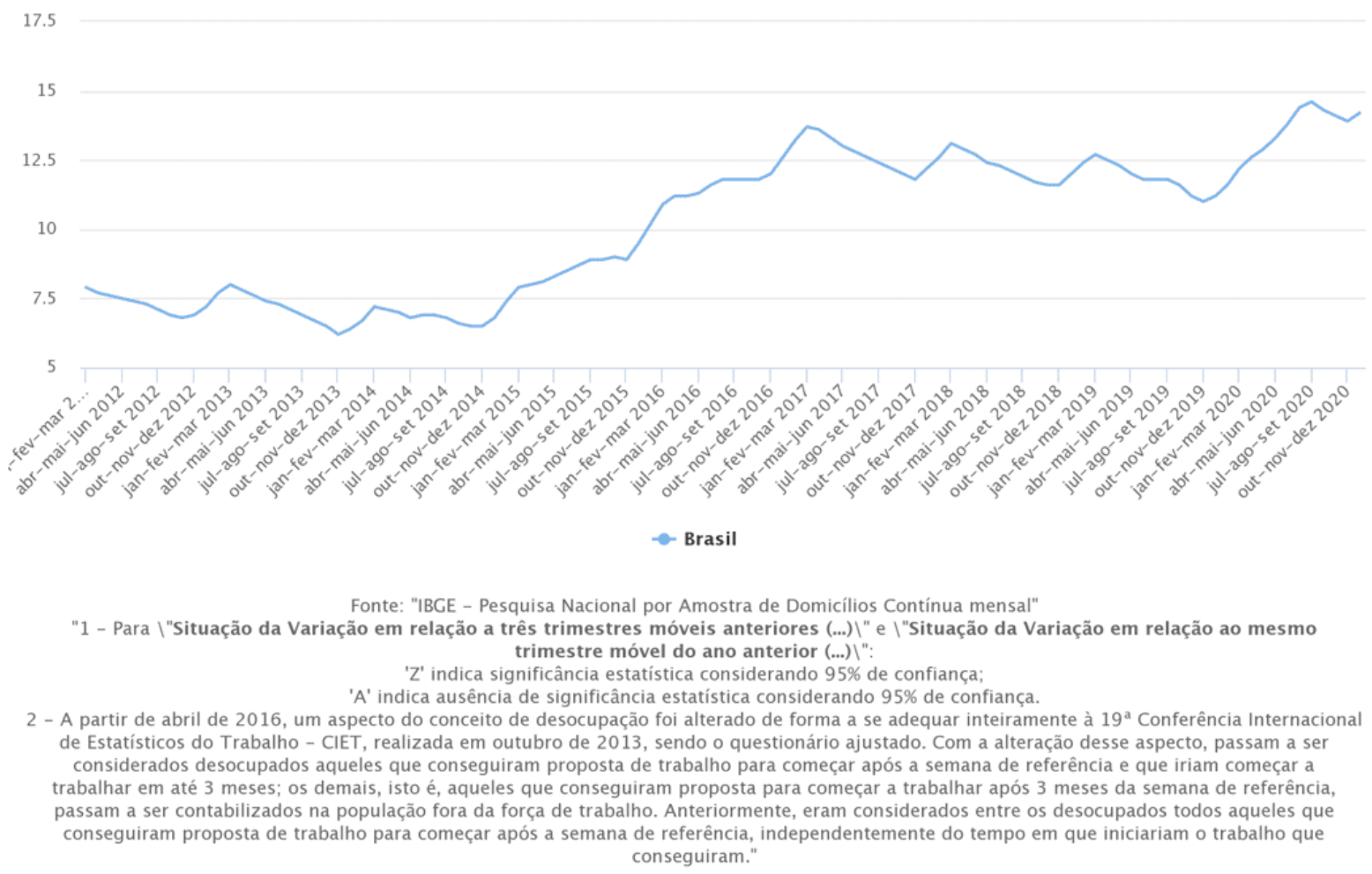

Fonte: ibge.gov.br

\section{REFERENCIAL TEÓRICO}

\subsection{O EMPREENDEDORISMO TRANSFORMADOR}

Segundo Baggio e Baggio (2014) o empreendedorismo no Brasil é uma riqueza pouco explorada, o potencial empreendedor do brasileiro poderia causar uma explosão de novas oportunidades e desenvolvimento econômico, e esse poder está nas mãos dos brasileiros. Para que isso aconteça alguns obstáculos precisam ser transpostos,

RC: 84394

Disponível em: https://www.nucleodoconhecimento.com.br/administracao/fomento-aoempreendedorismo 
como: melhorar a autoconfiança do empreendedor brasileiro; desenvolver abordagens próprias ao Brasil, que correspondem às características profundas da cultura brasileira; ser mais disciplinado; promover o compartilhamento de informações e por último minimizar a burocracia (FILION, 2000, p. 33).

De fato, assistimos o aumento de empreendedores brasileiros, e por conta disso, segundo Santos (2017), as sociedades políticas de desenvolvimento econômico regional, vem adotando novas estratégias para enfrentar a queda no número de empregos tradicionais e a inserção de novos jovens ao mercado de trabalho. Conforme os dados da Confederação Nacional do Comércio de Bens, Serviços e Turismo (2016), a maioria dos negócios em nosso país é representado pelas micro e pequenas empresas, que corresponde a $90,3 \%$ das empresas ativas em todo o Brasil, deixando claro a importância do empreendedorismo no desenvolvimento da economia local.

"Os brasileiros são vistos por muitos autores como potenciais empreendedores. A cultura do Brasil é a do empreendedor espontâneo. Este está onipresente. Ele só precisa de estímulo, como uma flor precisa do sol e um pouco de água para britar na primavera" (BAGGIO e BAGGIO, 2014, p, 2).

Uma pesquisa realizada em 2001, envolvendo cerca de 29 países, sobre a população entre 18 e 64 anos que se dedicam ao empreendedorismo, o Brasil aparece em $5^{\circ}$ lugar com o percentual de 14,2\% da população (CHIAVENATO, 2004, p. 11). O Brasil ocupa a 15a posição do Ranking do Empreendedorismo por Oportunidades e a $4^{\text {a }}$ posição no Ranking do Empreendedorismo por Necessidades, segundo pesquisa da GEM - Global Entrepreneurship Monitor realizada em 2005 em 36 países.

Leite e Oliveira (2007) classificam em dois tipos de Empreendedorismo: o Empreendedorismo por Necessidade (criam-se negócios por não haver uma alternativa) e o Empreendedorismo por Oportunidade (descoberta de uma oportunidade de negócio lucrativa). O tema desta pesquisa debruça-se sobre o tipo

RC: 84394

Disponível em: https://www.nucleodoconhecimento.com.br/administracao/fomento-aoempreendedorismo 
do empreendedorismo por necessidade, que é o caso dos camelôs da cidade do Rio de Janeiro, que se acumulam pelas calçadas, sem estrutura, sem suporte, sem incentivos, muitas vezes à margem da lei, que percebem como diferente a sua realidade de vida a realidade de vida dos grandes empresários. Segundo Vieira (2012) a classe social mais pobre e miserável, que se concentra na base da pirâmide social, não ascendem, permanecem ali quase que de maneira estática. Os camelôs que integram essa faixa da pirâmide, se não receberem orientações de como empreender formalmente, dificilmente sairão desta posição desfavorável. É necessário a criação de um programa que trate desta ação transformadora, que fomente a criação das micro e pequenas empresas, que facilite o acesso ao crédito, que forneça treinamento técnico adequado, garimpando mentes empreendedoras. Investir no empreendedorismo é investir no desenvolvimento econômico e social do território.

A adoção de iniciativas como fomento ao empreendedorismo, inovação, tecnologia, acesso a serviços financeiros, formalização de pequenos negócios e uso do poder de compra público e privado ajudam a dinamizar a economia local, propiciando a fixação da renda ao desenvolvimento econômico do território (SANTOS, 2017, p. 5).

Mediante a sua ascensão na mobilidade social, o camelô que virou empresário David Portes já estuda a possibilidade de, em parceria com o Sebrae, transformar seu nome em marca. A franquia da Banca do David será uma rede de lojas de doces voltadas para o público de shoppings e quiosques e certamente carregará consigo as características de carisma e simpatia de seu idealizador (OLIVEIRA, 2006).

\subsection{A IMPORTÂNCIA DO INCENTIVO À FORMALIZAÇÃO DE NOVOS NEGÓCIOS E OS SEUS REFLEXOS NA ECONOMIA.}

O Serviço Brasileiro de Apoio às Micro e Pequenas (SEBRAE) detém larga experiência no incentivo, treinamento e desenvolvimento técnico aos empreendedores em todo o Brasil, o Sebrae tem como missão fomentar o desenvolvimento sustentável das micro e pequenas empresas, algo muito importante para nossa cidade, visto que esses negócios de pequeno porte representam $98 \%$ de RC: 84394

Disponível em: https://www.nucleodoconhecimento.com.br/administracao/fomento-aoempreendedorismo 
todas as empresas do país. Segundo esta entidade, em seu artigo publicado em 2015, "Ser empreendedor não é condição exclusiva de empresários ou de quem está à frente dos negócios. Tem a ver com atitudes que determinadas pessoas desenvolvem" (SEBRAE, 2015). Para o pesquisador canadense e um dos maiores especialistas na área, Louis Jacques Filion, o empreendedor é uma pessoa que imagina, desenvolve e realiza visões. Ou seja, alguém que pensa, planeja e age, arquitetando todas essas etapas de maneira estratégica para conquistar metas e objetivos.

Embora Vieira (2012) afirme que é improvável que um indivíduo, vindo da base da pirâmide social, alcance o topo da mesma, é inegável que muitos dos vendedores ambulantes das ruas da cidade, que iniciaram suas atividades empreendedoras por necessidade, podem se tornar empresários, não precisando necessariamente alcançar o topo da pirâmide social, mas sim movimentar-se dentro dela, ajudando no desenvolvimento econômico da sua cidade, gerando renda, novos empregos com carteira assinada. Sou servidor público a 14 anos e atuando como Agente de Inspeção de Controle Urbano nas ruas da cidade do Rio de Janeiro, pude perceber o quanto revelaram-se criativos e talentosos, alguns camelôs da cidade. É verdade que este programa não alcançaria grande parte dos ambulantes, pois nem todos teriam as características necessárias para virarem empresários, porém o mínimo de esforço estatal que se comprometa a propor a esta classe de empreendedores esta possibilidade de transformarem-se em empresários, pode propiciar a criação de um ambiente de negócios benéfico para ambas as partes, tanto pro governo quanto pro vendedor ambulante, impactando em toda a sociedade territorial. O momento econômico de crise sugere que os governos municipais adotem medidas empreendedoras. O olhar holístico acerca dos camelôs deve ser atualizado, não é mais possível manter o entendimento de que todo camelô ostenta status de precariedade, de pobre coitado. No contexto do comércio de rua existem vários perfis de indivíduos, dentre eles está o perfil do empresário.

RC: 84394

Disponível em: https://www.nucleodoconhecimento.com.br/administracao/fomento-aoempreendedorismo 
O Sebrae mantém o projeto Cidade Empreendedora, onde as parcerias entre moradores, governo e empresários estimulam o desenvolvimento econômico municipal através da adoção de medidas específicas e estratégicas, melhorando o ambiente de negócios. Dentre as estratégias de ações estão: Gestão municipal, com prioridade na geração de empregos; Mobilização de lideranças locais; Desburocratização facilitando a abertura de empresas; Implementação de salas de aulas para empreendedores; Estímulo à participação nas compras públicas, por parte das pequenas empresas; Educação empreendedora, incentivando o empreendedorismo através da educação; Inclusão produtiva inclusão e renda para quem mais precisa; Promoção do Marketing Territorial e Setores Econômicos, fortalecendo o empreendedor para que haja mais emprego, renda e educação; Apoio ao Cooperativismo e ao Crédito; Inovação e Sustentabilidade. Este programa corresponde às iniciativas municipais de estímulo ao desenvolvimento econômico territorial, com a geração de empregos e de renda através do fomento ao empreendedorismo.

Para Santos (2017) "As prefeituras precisam criar um plano estruturado para que possa viabilizar ações que contribuam para o crescimento do local, e possa disseminar um círculo contínuo de expansão, buscando despertar e definir as vocações que cada região possui". Nesse contexto a Prefeitura da Cidade do Rio de Janeiro tem um celeiro riquíssimos de empreendedores que hoje estão empreendendo nas ruas, conforme conclui Baggio e Baggio (2014), entretanto, se for implementado um programa que busque encontrar e qualificar novos empresários, novos empregos serão criados, melhorando a renda e trazendo desenvolvimento econômico. Na mesma linha, Kliksberg (2001), ressalta que o Estado possui papel importante no desenvolvimento e na criação do capital social, identificando os atores e suas contribuições ao coletivo, já que o Estado é um articulador entre as instituições públicas, sindicatos, não governamentais, fundações empresariais, dentre outras organizações.

RC: 84394

Disponível em: https://www.nucleodoconhecimento.com.br/administracao/fomento-aoempreendedorismo 


\subsection{OS RESULTADOS DE PARCERIAS PELAS CIDADES DO BRASIL}

Por várias cidades do Brasil, o Sebrae atua em parceria com os gestores municipais promovendo o desenvolvimento econômico local, investindo e incentivando o empreendedorismo na criação de micro e pequenas empresas. Suas ações e resultados fazem parte do programa Prefeito Empreendedor, com entrega de prêmios as prefeituras que mais se destacaram naquele período. Como exemplo podemos citar o caso da Prefeitura de Volta Redonda/RJ que antes de participar do projeto Prefeito Empreendedor apresentava lentidão e muita burocracia pra se abrir uma empresa naquela cidade; havia um grande número de ambulantes trabalhando de forma desordenada e na informalidade mantendo uma economia paralela, sem controle, sem arrecadação, sem orientação ou capacitação; dificuldades de se obter crédito para os pequenos negócios junto às instituições financeiras; os produtores rurais não participavam do fornecimento de merenda escolar; os pequenos negócios não participavam das licitações públicas.

As soluções propostas pelo município foi a regulamentação do comércio e serviços dos ambulantes; isentou o IPTU dos imóveis residenciais com fins comerciais para MEIs (Micro Empreendedor Individual); promoveu eventos para fomentar a economia solidária, favorecendo os setores da gastronomia e o de food trucks; definiu um local específico para os ambulantes trabalharem de forma legalizada; formalizou uma parceria com a entidade financeira AgeRio o que facilitou o acesso ao crédito aos micro e pequenos empreendedores, além de adotar outras medidas de inclusão econômica e produtiva.

Os exemplos de parcerias entre governos municipais e o Sebrae são muitos Brasil afora, entretanto, cabe ao poder estatal se mobilizar para fazer a diferença em suas cidades promovendo ambientes de negócios, com inclusão social e desenvolvimento econômico local. Granja (2010) afirma que o desenvolvimento local promove a qualidade de vida das pessoas daquele município, à medida que potencializa as

RC: 84394

Disponível em: https://www.nucleodoconhecimento.com.br/administracao/fomento-aoempreendedorismo 
particularidades encontradas na cidade. Baggio e Baggio (2014) acrescenta ainda que:

O empreendedorismo social é um misto de ciência e arte, racionalidade e intuição, ideia e visão, sensibilidade social e pragmatismo responsável, utopia e realidade, força inovadora e praticidade. $O$ empreendedor social subordina o econômico ao humano, o individual ao coletivo e carrega consigo um grande sonho de transformação da realidade atual (BAGGIO e BAGGIO, 2014, p. 6).

As ações da prefeitura da cidade do Rio de Janeiro em parceria com o Sebrae, empreendedores e a população, através de um novo olhar nas relações entre governo e empreendedores ambulantes, pode ser entendido como empreendedorismo social. Para Baggio e Baggio (2014), o processo de empreendedorismo social exige do governo uma mudança nas relações entre governo, setor privado, sociedade, obtendo-se como resultado final a promoção na qualidade de vida social, econômica, cultural, e ambiental sob a ótica da sustentabilidade. Para AIUB (2002) a necessidade de criar oportunidades de negócios, via enriquecimento da diversidade da matriz econômica e da constituição de novos empreendimentos que atribuam uma dinâmica autogeradora de trabalho e riqueza, faz da estratégia de incentivar o empreendedorismo uma importante alternativa de desenvolvimento econômico. De acordo com tal entendimento, é confortável afirmar que a prefeitura da cidade do Rio de Janeiro, ao adotar uma postura diferente no trato com os empreendedores ambulantes, quebrando com o entendimento holístico de que o camelô atual mantêm necessariamente um Status de "pobre coitado", e com isso negando ao mesmo a possibilidade de demonstrar suas capacidades, suas vocações empreendedoras, certamente estará também, não apenas resolvendo uma questão de desenvolvimento econômico, mas sim alterando, influenciando na mobilidade social do nosso país. Os gestores municipais precisam entender que os atuais empreendedores ambulantes (antigos camelôs) devem deixar de representar apenas problemas para a cidade, e devem passar a serem vistos como possíveis parceiros no desenvolvimento econômico, social e cultural. Contribuindo para criação de empregos formais, gerando riqueza local, contribuindo para a arrecadação do município.

RC: 84394

Disponível em: https://www.nucleodoconhecimento.com.br/administracao/fomento-aoempreendedorismo 


\section{PLANO DE AÇÃO}

Para abordarmos o problema da pesquisa deste trabalho será adotada a metodologia $5 \mathrm{~W} 2 \mathrm{H}$ ou $5 \mathrm{~W} 1 \mathrm{H}$, já que o custo só será definido ao curso do processo, a partir das escolhas das soluções apresentadas pelo Sebrae/RJ e pela Prefeitura da Cidade do Rio de Janeiro.

Quadro 1: 5W1H

\begin{tabular}{|c|c|}
\hline Etapa & Descrição \\
\hline O quê? & $\begin{array}{l}\text { Criar um plano de ação, visando transformar empreendedores } \\
\text { ambulantes em possíveis empresários. }\end{array}$ \\
\hline Por quê? & $\begin{array}{l}\text { Para disseminar a cultura empreendedora; fomentar a criação de micro } \\
\text { e pequenas empresas; aumentar a arrecadação aos cofres públicos; } \\
\text { aumentar o número de vagas com carteira assinada; diminuir a } \\
\text { concentração de ambulantes nas ruas; promover o desenvolvimento } \\
\text { econômico local; geração de riqueza. }\end{array}$ \\
\hline Quem? & $\begin{array}{l}\text { A prefeitura em parceria com } 0 \text { Sebrae/RJ, setor privado e } \\
\text { comerciantes ambulantes. }\end{array}$ \\
\hline Onde? & Na cidade do Rio de Janeiro. \\
\hline Quando? & Ao fim da atual Pandemia provocada pelo CORONAVÍRUS. \\
\hline Como? & $\begin{array}{l}\text { 1) Promoção de amplo debate e elaboração de um roteiro; } \\
\text { 2) Convidar e cadastrar, os possíveis candidatos a micro e pequenos } \\
\text { empresários. } \\
\text { 3) Capacitar os multiplicadores da cultura empreendedora; } \\
\text { 4) Traçar a vocação econômica local; } \\
\text { 5) Identificar os candidatos a empresários; }\end{array}$ \\
\hline
\end{tabular}

RC: 84394

Disponível em: https://www.nucleodoconhecimento.com.br/administracao/fomento-aoempreendedorismo 
6) Sensibilizar os empresários às parcerias;

7) Definir por setores o curso das ações de aprendizagem. De acordo com a vocação de cada candidato, e da vocação econômica da região.

8) Incentivar o cooperativismo.

9) Trabalhar o comportamento empreendedor;

10) Definição de cronograma;

11) Definição de parcerias;

12) Gerar indicadores.

Quanto O custo desse plano de ação envolve os gastos de cada etapa, que custa? possui um valor diferente para cada setor de aprendizagem.

Fonte: Autor.

O objetivo deste trabalho é propor à Prefeitura da cidade do Rio de Janeiro, em parceria com o Sebrae/RJ, a criação de um sistema catalisador, através de agentes imbuídos na missão de fomentar o empreendedorismo, onde seja possível identificar e capacitar, transformando vidas, incentivando a economia local, gerando riquezas e renda para população carioca, a partir do aproveitamento do instinto e da vocação de empreendedores que hoje empreendem por necessidade nas ruas da cidade. Atualmente há muitos negócios informais que já funcionam nas ruas da cidade e se mostram bem estruturados, com um ciclo laboral estabelecido, empregando informalmente cerca de 2 a 5 funcionários, sustentando uma economia paralela. Nesses casos falta à gestão municipal apenas a assunção da responsabilidade sobre tais atividades, estabelecendo as regras de funcionamento, submetendo - os às fiscalizações necessárias, garantindo a segurança e o direito dos consumidores, trazendo o comércio informal à formalidade.

RC: 84394

Disponível em: https://www.nucleodoconhecimento.com.br/administracao/fomento-aoempreendedorismo 
Inicialmente seria realizado um amplo debate, envolvendo integrantes da prefeitura, do Sebrae e de entidades representativas dos ambulantes, com o intuito de estudar a viabilidade deste projeto, e conferir a possibilidade de trazer para formalidade pequenos negócios, onde empreendedores por necessidade, que no geral, não tiveram acesso a informações relativas ao desenvolvimento do empreendedorismo formal, não tiveram instrução, treinamento e que estão à margem da lei. Estabelecer e identificar possíveis perfis de ambulantes e/ou negócios, de acordo com seus tipos de mercadorias, que estejam aptos a se enquadrarem e receberem as instruções e treinamentos previstos e elaborados especificamente pela equipe técnica do Sebrae. Na sequência será estabelecido um roteiro definindo o passo a passo das ações que serão postas em prática, após o período da pandemia atual, provocada pelo Coronavírus.

Dando continuidade, atendendo ao item 2, a prefeitura publicaria um edital contendo as regras e condições que verse sobre o tema do projeto, para a seleção de candidatos possivelmente aptos, que conforme interesse, apresentar-se-iam, de acordo com características pré-definidas, tipo: "os que trabalhem com alimentos", em datas pré-determinadas, a fim de se identificarem, se cadastrarem e responderem um formulário de perguntas, conforme interesse, para fases futuras a se realizarem em período posteriormente definido. Essa pode ser uma fase que consuma inicialmente muito tempo do projeto, porém os resultados obtidos serão de suma importância para a continuidade do trabalho.

Esse será um projeto-piloto envolvendo personagens que estão habituados aos ambientes formais, tanto por parte dos profissionais do Sebrae quanto por parte do governo municipal, porém, incluiremos nesse entremeio uma classe de trabalhadores que desenvolvem suas atividades comerciais pelas ruas da cidade, sem preparo, sem organização e sem visão adequada do negócio formal, portanto há de se haver uma capacitação e um preparo adequado dos técnicos que lidarão e terão a responsabilidade de aplicar os ensinamentos ao grupo selecionado. O objetivo geral

RC: 84394

Disponível em: https://www.nucleodoconhecimento.com.br/administracao/fomento-aoempreendedorismo 
deste projeto é aumentar a arrecadação local, trazendo para a formalidade os pequenos negócios que hoje não contribuem para os cofres públicos, gerando riqueza, empregos com carteira assinada, além de promover mudança comercial e social na vida destes empreendedores. Para tanto a habilidade destes profissionais que lidarão com os camelôs precisa de atenção, dada a demanda que se avulta.

Cada região da cidade mantém uma vocação comercial que mais se destaca. Neste momento os agentes envolvidos do Sebrae e da Prefeitura definirão o tipo de comércio que mais se enquadre nesta ou naquela região. Nesta fase serão identificados os tipos e a quantidade dos futuros pequenos empreendimentos, respeitando a capacidade de absorção de cada região analisada. Segundo a Secretaria Municipal de Fazenda e Planejamento, atualmente a Cidade do Rio de Janeiro possui 9.359 vendedores ambulantes registrados nas mais diversas categorias previstas pela legislação. Eles estão nas praias e divididos pelas 9 gerências de licenciamento de fiscalização. Conforme o gráfico abaixo, o Centro da cidade concentra o maior número de ambulantes registrados, seguido pela Gerência Regional de Licenciamento e Fiscalização (GRLF) da Gávea que responde também por grande parte da Zona Sul. Em terceiro aparece a regional da Zona Norte que contempla 1440 ambulantes autorizados, grande parte deles concentrados no bairro de Madureira.

RC: 84394

Disponível em: https://www.nucleodoconhecimento.com.br/administracao/fomento-aoempreendedorismo 
Gráfico 02: Quantidade de ambulantes registrados na Prefeitura do Rio de Janeiro.

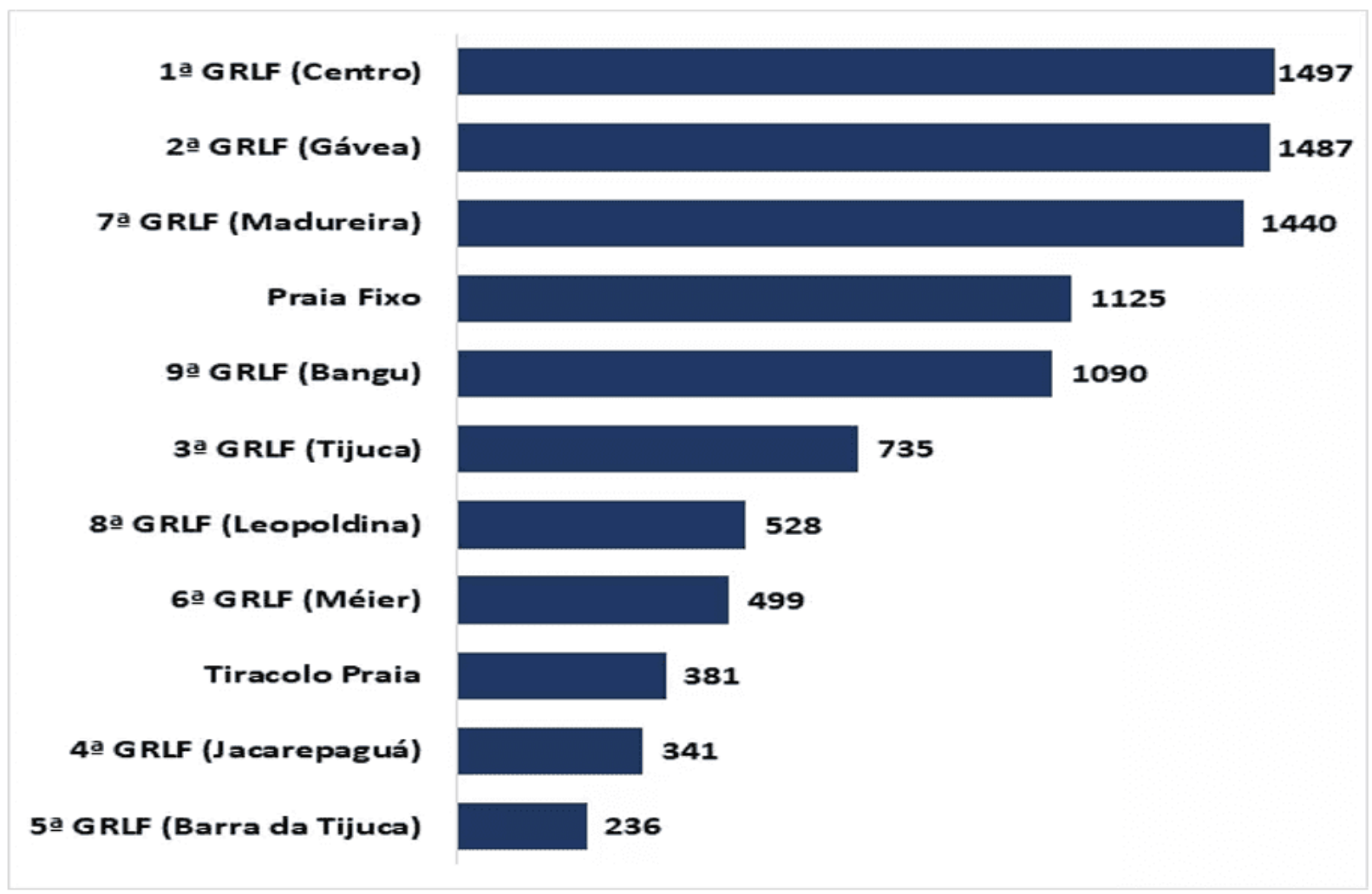

Fonte: Secretaria Municipal de Fazenda e Planejamento. Análise: Instituto Rio 21.

A $5^{\underline{a}}$ etapa constituirá a fase de identificação dos futuros empresários, definindo suas vocações, suas áreas onde se instalarão seus comércios. Nesta fase será dado início ao treinamento e aos cursos que objetivarão torná-los empresários.

Um grande projeto que vise promover uma mudança inovadora nas relações sociais e econômicas, de uma parcela significativa de pessoas e de uma cidade, que contará com o apoio do Sebrae, são de maneiras gerais acompanhadas de parcerias. $\mathrm{O}$ importante desta fase será fomentar as possíveis parcerias entre os negócios já existentes, com os que possivelmente surgirão. Além de incentivar outros tipos de parcerias, inclusive o cooperativismo entre as que estão surgindo. Essas parcerias são de suma importância para o sucesso deste projeto, uma vez que corroboram para um bom resultado.

RC: 84394

Disponível em: https://www.nucleodoconhecimento.com.br/administracao/fomento-aoempreendedorismo 
Definir por setores o curso das ações de aprendizagem. De acordo com a vocação de cada candidato, e da vocação econômica da região. A inclusão de conteúdo peculiar a cada setor demanda preparo antecipado dos técnicos envolvidos, para tanto é necessário que haja definição no curso que será dado a todas as ações de aprendizagem, atendendo as vocações de cada tipo de perfil de candidatos, garantindo eficácia ao processo de preparação. Cada região econômica detém vocação característica e este fator deve ser considerado para que os objetivos sejam alcançados.

A possibilidade do cooperativismo deve ser apresentada como opção aos produtores que se encontram espalhados pela cidade, explicar sobre as vantagens de trabalharem juntos, o aumento da produção, as possibilidades de crédito junto a instituições financeiras, criadas para este projeto ou as já existentes, ampliando seus conhecimentos sobre exportação e importação. Muitos pontos sobre o cooperativismo devem ser abordados e discutidos, para tanto é necessário que os futuros micro e pequenos empresários entendam e adiram ao treinamento proposto. O sucesso para os que estiverem dispostos ao cooperativismo dependerá da dedicação.

Trabalhar as peculiaridades individuais a serem observadas neste processo de transformação e aprendizado dos indivíduos em questão é muito importante, logo o comportamento empreendedor deve ser tratado como crucial neste processo. As práticas comportamentais anteriores dos indivíduos que imbricam ao novo perfil empreendedor, devem ser atualizadas por novos comportamentos. Adquirir conhecimento relacionado ao trato comercial com outros empreendedores, assim como assimilar linguajar, trejeitos pessoais e postura mais adequada à nova realidade comercial pretendida, corroborará na construção do novo perfil vencedor deste empreendedor.

Para darmos andamento aos trabalhos, dividiremos em etapas os movimentos entendidos como essenciais para o desenvolvimento deste projeto, para tanto, será elaborado um cronograma, contendo o passo a passo a ser executado durante o RC: 84394

Disponível em: https://www.nucleodoconhecimento.com.br/administracao/fomento-aoempreendedorismo 
desenvolvimento deste. Dentre as diversas etapas previstas, algumas poderão ser concebidas simultaneamente, desde que não tragam prejuízo ao objetivo final ou embacem outra fase que já esteja em andamento. A decisão sobre a simultaneidade das ações ficará a cargo dos elaboradores deste projeto, que configuraram este cronograma.

As buscas por parcerias poderá ser um atrativo para empresas afins já constituídas, uma vez que a gestão municipal poderá, através de incentivos fiscais ou outros tipos de vantagens, propor tais direcionamentos a esses negócios. O objetivo desta ação será o de aproximá-los e incentivá-los a consumirem entre si produtos e serviços produzidos, facilitando a inclusão do plano de ação destes novos negócios à formalidade. Neste caso a própria prefeitura poderá tornar-se consumidora de algum produto ou serviço oferecido pelo novo empreendedor formal, como o fornecimento de merenda escolar, observando as regras licitatórias que envolvem um ente público.

Acompanhar, através da criação de indicadores, todo o processo de desenvolvimento e aplicação deste projeto, monitorando os resultados obtidos junto aos novos negócios, revendo novos conceitos, atualizando resultados e promovendo o ajuste onde se fizer necessário para o sucesso deste projeto-piloto.

Quanto ao custo deste projeto é impossível determinar, visto que parte das soluções advirão de reuniões que ocorrerão em auditórios, tanto da Prefeitura da Cidade do Rio de Janeiro, quanto do Sebrae, e uma vez que ambos estando imbuídos em dar sequência a este plano de ação, essa fase não trará ônus significativos aos cofres públicos. Quanto à divulgação e a publicidade dos resultados de cada fase seletiva entre os candidatos, o Diário Oficial do Município, que diariamente é publicado no site da prefeitura, poderá elencar tais informações otimizando qualquer custo referente às publicações. Sobre a recepção e o atendimento dos camelôs, candidatos a futuros empreendedores formais, a prefeitura e o Sebrae dispõem de estrutura física e de quadro próprio de pessoal, capazes de realizarem esta recepção sem que esta fase gere despesa desnecessária. Quanto aos instrutores que participarão da fase do RC: 84394

Disponível em: https://www.nucleodoconhecimento.com.br/administracao/fomento-aoempreendedorismo 
ensino e treinamento, os valores acordados poderão ser definidos por etapa, ao passo em que forem sendo implementadas as fases com a evolução do plano de ação. Embora quaisquer outras despesas possam ocorrer no curso deste plano de ações, são inicialmente impossíveis de serem previstas. No entanto, caso vierem a surgir, medidas serão tomadas a fim de minimizar tais impactos indesejáveis.

\section{CONCLUSÃO}

A ausência de uma política pública mais adequada e direcionada ao desenvolvimento econômico, centralizado na figura do vendedor ambulante, que atualmente exerce um comércio que, em sua grande maioria, acontece à margem da lei, driblando as leis do Estado, trazendo prejuízos para a arrecadação fiscal municipal, além de não atender às obrigações trabalhistas, vem exigindo dos gestores municipais mais atenção para a situação da desordem urbana. Neste artigo procurou-se trazer à tona as deficiências de um modelo de concepção de conceito cidade, que hoje se mostra desatualizado, insuficiente e incapaz de apresentar propostas ou resultados mais eficientes para o cenário urbano atual da desordem que se observa. Neste trabalho foi apresentado um projeto-piloto contendo um plano de ação, onde o governo municipal da Cidade do Rio de Janeiro assume novo entendimento acerca da apropriação da área pública, passando a considerar as atuais práticas urbanas no processo de apropriação do espaço público. Consequentemente, apreende-se novo entendimento da figura do camelô, que até então sustentava o status de coitado, passando a ser entendido como empreendedor por necessidade.

A partir da nova concepção do indivíduo como empreendedor, a prefeitura da Cidade do Rio de Janeiro em parceria com o Sebrae/RJ, adotará o plano de ação previsto neste projeto. A adoção por parte da prefeitura do Rio deste plano de ação inovador, demonstrará postura empreendedora por parte da cidade. Este projeto concentra os objetivos de selecionar, treinar e capacitar possíveis novos empreendedores por necessidade, que atualmente empreendem de forma irregular nas ruas cariocas, sem

RC: 84394

Disponível em: https://www.nucleodoconhecimento.com.br/administracao/fomento-aoempreendedorismo 
estrutura, sem preparo e sem visão dos benefícios que um negócio formal o pode trazer. Estes terão suas vocações comerciais desenvolvidas e terão apoio técnico, assim como treinamento sobre como tornarem-se micro e pequenos empresários, criando ambientes de negócios, gerando riqueza local, gerando empregos com carteira assinada, contribuindo para a arrecadação de impostos, aquecendo a economia local. Como num efeito cascata, a formalização de negócios ora integrantes de uma economia paralela, que não contribui para a arrecadação fiscal do município, e que não atende as obrigações das leis trabalhistas, ajudará no financiamento das políticas públicas ligadas à saúde, educação, segurança, saneamento básico, transporte, entre outras de interesse do povo. Uma economia paralela sufoca o comércio formal, uma vez que os governantes muitas vezes se veem obrigados a aumentar impostos, para conseguirem atender as demandas da população.

\section{REFERÊNCIAS}

AIUB, G. W. Inteligência Empreendedora: Uma Proposta de Capacitação de Multiplicadores da Cultura Empreendedora. UFSC, Florianópolis, 2002.

BAGGIO, A. F.; BAGGIO, K. D. Empreendedorismo: Conceitos e Definições. Revista de Empreendedorismo, Inovação e Tecnologia. 1(1): 25-38, 2014 - ISSN 2359-3539. p. 25. Disponível em: <https://doi.org/10.18256/2359-3539/reitimed.v1n1p25-38>. Acesso em: 28 de outubro de 2020.

CHIAVENATO, I. Empreendedorismo: dando asas ao espírito empreendedor. São Paulo: Saraiva. 2004. 332p.

CNN BRASIL. Por pandemia, 50 mil empresas de turismo fecharam no Brasil entre março e agosto. Disponível em: $<$ https://www.cnnbrasil.com.br/business/2020/10/03/por-pandemia-50-mil-empresasde-turismo-fecharam-no-brasil-entre-marco-e-agosto> Acesso em: 17 de fevereiro de 2021.

RC: 84394

Disponível em: https://www.nucleodoconhecimento.com.br/administracao/fomento-aoempreendedorismo 
FERREIRA, A. Ex-camelô que virou palestrante dá 10 lições de empreendedorismo.

<https://economia.uol.com.br/noticias/redacao/2012/05/14/ex-camelo-que-viroupalestrante-da-10-licoes-de-empreendedorismo.htm>. Acesso em 04 de abril de 2021.

FILION, L. J. Diferenças entre sistemas gerenciais de empreendedores e operadores de pequenos negócios. Revista de Administração de Empresas, v. 39, n. 4, out-dez, p.6-20, 1999. Disponível em: <http://dx.doi.org/10.1590/S003475901999000400002>. Acesso em: 15 de fevereiro de 2021.

GRANJA, S. I. B. Elaboração e avaliação de projetos. Florianópolis: Departamento de Ciências da Administração / UFSC; [Brasília]: CAPES: UAB, 2010. 122p.

HARVEY, D. Condição pós-moderna. São Paulo. Edições Loyola 1992. 352p.

HISRICH, R. D.; PETER, M. P. Empreendedorismo. Porto Alegre. Editora Bookman. 2004. 480p.

KLIKSBERG, B. Falácias e mitos do desenvolvimento social. Brasília. 2001. 175p.

OLIVEIRA, M. O marketing intuitivo do camelô que virou empresário. 2006. Disponível em: https://www.mundodomarketing.com.br/reportagens/planejamentoestrategico/199/o-marketing-intuitivo-do-camelo-que-virouempresario.html\#: :text=Mesmo\%20sem\%20ter\%20completado\%20o,e\%20ser\%20 ousado\%E2\%80\%9D\%2C\%20conta. Acesso em: 13 de março de 2021.

RAMMÉ, J. Desenvolvimento municipal: Análise da dinâmica populacional da mesorregião do oeste catarinense. Estudos do CEPE, Santa Cruz do Sul, p. 242262, dez. 2011. ISSN 1982-6729.

SANTOS, R. G. dos. Crescimento endógeno e singular de um território por meio das micro e pequenas empresas do setor de moda do Estado do Rio de Janeiro.

RC: 84394

Disponível em: https://www.nucleodoconhecimento.com.br/administracao/fomento-aoempreendedorismo 
Universidade Federal Fluminense: Volta Redonda, 2017. Disponível em: https://app.uff.br/riuff/bitstream/1/6387/1/Raquel\%20Gomes\%20dos\%20Santos.pdf. Acesso em: 07 de março de 2021.

SCHUMPETER, J. A. Capitalismo, Socialismo e Democracia. Rio de Janeiro: Editora Fundo de Cultura, 1961. 488p. Disponível em: https://www.institutomillenium.org.br/wp-content/uploads/2013/01/Capitalismosocialismo-e-democracia-Joseph-A.-Schumpeter.pdf. Acesso em: 06 de janeiro de 2021.

SEBRAE. Conheça características importantes para o comportamento empreendedor. Disponível em: https://www.sebrae.com.br/sites/PortalSebrae/artigos/artigoshome/conhecacaracteris ticasimportantes-para-ocomportamentoempreendedor,638b5d27e8fdd410VgnVCM1000003b74010aRCRD. Acesso em: 12 de fevereiro de 2021.

SEBRAE. Prêmio Sebrae Prefeito Empreendedor. Disponível em: https://www.prefeitoempreendedor.sebrae.com.br/. Acesso em: 07 de abril de 2021.

TERRA. De camelô a bilionário, conheça a trajetória de Silvio Santos. [Internet]. Disponível na internet em: https://www.terra.com.br/economia/vida-de-empresario/decamelo-a-bilionario-conheca-trajetoria-de-silviosantos,f79e6b9dcf37a410VgnVCM4000009bcceb0aRCRD.html\#: :text=Aos\%2020 \%20anos\%2C\%200\%20jovem,R\%C3\%A1dio\%20Nacional\%20de\%20S\%C3\%A30\% 20Paulo. Acesso em: 07 de abril de 2021.

VENTURA, L. Rio de Janeiro tem mais de 9 mil ambulantes registrados. Disponível em: $\quad<$ https://diariodorio.com/rio-de-janeiro-tem-mais-de-9-mil-ambulantesregistrados/>. Acesso em: 13 de abril de 2021. 
VIEIRA, R. M. Apropriação estratégica e ideológica do fluxo ascendente da mobilidade social na motivação profissional: Uma dimensão de cooptação dos trabalhadores. Londrina. Germinal: Marxismo e Educação em Debate v. 3, n. 2, p. 81-92; dez. 2011.

\section{APÊNDICE - REFERÊNCIA DE NOTA DE RODAPÉ}

2. Bloqueio que, imposto pelo Estado ou por uma ação judicial, restringe a circulação de pessoas em áreas e vias públicas, incluindo fechamento de fronteiras, geralmente ocorre em situações de pandemia com o intuito de evitar a disseminação do vírus; confinamento: alguns estados brasileiros já se encontram em lockdown. Fonte: https://www.dicio.com.br/lockdown/. Acesso em: 18 de abril de 2021.

Enviado: Abril, 2021.

Aprovado: Maio, 2021. 